\title{
SOSIALISASI METODE BELAJAR MENYENANGKAN (FUN LEARNING) UNTUK MENINGKATKAN PEMAHAMAN KOSA KATA BAHASA INGGRIS PADA ANAK USIA DINI
}

\section{FUN LEARNING METHOD SOSIALIZATION IN INCREASING THE UNDERSTANDING OF ENGLISH VOCABULARY FOR EARLY CHILDREN}

\author{
Safnidar Siahaan ${ }^{1}$, Aulia Putri ${ }^{2}$, Desi Surlitasari Dewi ${ }^{3}$ \\ (Prodi, Pendikan Bahasa Inggris, Universitas Riau Kepulauan, Indonesia) \\ ${ }^{1}$ kirei_akiko83@yahoo.com, ${ }^{2}$ auliaputri1983@yahoo.com, ${ }^{3}$ belldaisy46@gmail.com
}

\begin{abstract}
Abstrak
Kegiatan pengabdian masyarakat merupakan bentuk sosialisasi dan pembelajaran dengan metode yang menyenangkan bagi anak-anak usia dini untuk meningkatkan pemahaman kosakata Bahasa Inggris. Dengan menggunakan metode ini diharapkan memberikan pengetahuan tentang kebutuhan penguasaan kosakata, maka jika anak melanjutkan pendidikan ke jenjang yang lebih tinggi mereka tidak akan mengalami kesulitan. Kegiatan ini dilakukan di RW 03 Desa Sungai binti, Kecamatan Sagulung. Metode yang digunakan adalah Pengajaran Bahasa Inggris dengan menggunakan lagu. Ini adalah salah satu metode / cara untuk mengajar Bahasa Inggris dengan menggunakan lagu sebagai medianya. Belajar dilakukan dengan metode belajar yang menyenangkan dan santai. Hasil pengajaran Bahasa Inggris yang dilakukan memberikan beberapa kemajuan, pertama; anak-anak di RW 03, Desa Sei Binti, Kecamatan Sagulung, Batam, mulai mengenali metode menghafal 10 kata sehari dalam belajar Bahasa Inggris, kedua; anak-anak tertarik untuk belajar Bahasa Inggris dan berlomba menghafal kosa kata yang diuji, yang terakhir; anak-anak di RW 03, Desa Sei Binti, Kecamatan Sagulung, Batam, dapat mengucapkan kata-kata sederhana dalam Bahasa Inggris dengan jelas.
\end{abstract}

Kata Kunci; Sosialisasi, Metode Belajar Menyenangkan, Kosa Kata, Pendidikan Anak Usia Dini

\begin{abstract}
This community service activity is in the form of socialization and learning with fun methods for early children to improve English vocabulary understanding. By using this method is expected providing the knowledge of vocabulary mastery needs, and then if the children continue their education to the higher level they will not have difficulties. This activity was carried out in RW 03 Sungai Binti Village, Sagulung sub-district. The method used is Teaching English by using the song. It is one of the methods / ways to teach English using song as its medium. Learning is done by fun learning method and relaxed. The results of the teaching of English conducted provide some progress, first; children in RW 03, Sei Binti Village, Sagulung Subdistrict, Batam, began to recognize the method of memorizing 10 words a day in learning English, second; the children interested to study English and competed in memorizing the vocabulary tested, the last; the children in RW 03, Sei Binti Village, Sagulung District, Batam, can say the simple words in English clearly.
\end{abstract}

Keywords; Socialization, Fun Learning Methods, Vocabulary, Early Children Education,

\section{PENDAHULUAN}

Bahasa Inggris merupakan bahasa internasional dunia. Hampir seluruh negara di dunia mempelajari Bahasa Inggris untuk berkomunikasi satu sama lain. Oleh karena itu, di 
zaman modern ini Bahasa Inggris menjadi hal yang wajib dipelajari sejak dini (Hoed, 2014). Pembelajaran sejak dini sangat dianjurkan karena daya tangkap yang masih sangat cepat dibandingkan masa-masa lainnya. Pendidikan usia dini dapat dilakukan melalui pemberian rangsangan untuk membantu pertumbuhan dan perkembangan jasmani dan rohani agar anak memiliki kesiapan dalam memasuki pendidikan lebih lanjut. Pada umumnya aspek yang dikembangkan dalam pendidikan anak usia dini adalah aspek pengembangan perilaku dengan pembiasaan. Aspek tersebut meliputi sosial, emosi, kemandirian, nilai moral, dan agama; serta pengembangan kemampuan dasar, yang meliputi pengembangan bahasa, kognitif, seni, dan fisik motorik. Dilihat dari aspek perkembangan bahasa, aspek tersebut ditujukan agar anak mampu mengungkapkan pikiran melalui bahasa yang sederhana secara tepat, mampu berkomunikasi secara efektif dan membangkitkan minat untuk dapat berbahasa khususnya bahasa asing. Belajar bahasa asing yaitu Bahasa Inggris dirasa perlu untuk menunjang masa depan seseorang di zaman yang sangat ketat persaingan seperti saat ini.

Penting sekali memberikan pengenalan Bahasa Inggris mulai sejak dini. Dengan menguasai Bahasa Inggris maka orang akan dengan mudah masuk dan dapat mengakses dunia informasi dan teknologi. Sebagaimana yang dikemukakan oleh Steinberg dalam Fauziati (2010) bahwa anak-anak mempunyai kemampuan mengingat yang luar biasa khususnya usia 5-6 tahun. Sehingga masa tersebut adalah masa yang tepat dalam mengenalkan bahasa asing yang sesuai dengan kemampuan dan kebutuhan anak. Selain itu anak akan memiliki potensi untuk menjadi lebih baik dimasa mendatang jika potensi tersebut diberi rangsangan, bimbingan, bantuan dan perlakuan yang sesuai dengan tingkat pertumbuhan dan perkembangannya. Seperti yang diungkapkan oleh Megah dkk (2019) bahwa ada 4 faktor yang mempengaruhi anak-anak untuk termotivasi dan giat belajar yaitu adanya cita-cita, kemampuan, kondisi jasmani dan rohani, dan kondisi lingkungan. Dapat disimpulkan apabila ke empat faktor tersebut diberi rangsangan, bimbingan, bantuan dan perlakuan yang sesuai dengan tingkat pertumbuhan dan perkembangan maka akan menunjang masa depan anak untuk menghadapi persaingan yang ketat.

Adapun sasaran dari kegiatan ini adalah anak-anak yang ada pada RW 03 Kelurahan Sungai Binti Kecamatan Sagulung. Alasan pengajaran Bahasa Inggris diadakan di kavling Saguba RW 03 Kelurahan Sungai Binti ialah untuk memberikan kebutuhan pengetahuan 
penguasaan kosakata yang banyak sehingga apabila anak melanjutkan jenjang pendidikan ke tingkat yang lebih tinggi mereka tidak akan mengalami kesulitan. Oleh karena itu, fokus utama dalam pengajaran Bahasa Inggris ini ialah penguasaan kosakata. Dengan menguasai kosakata yang banyak maka anak-anak dapat dengan mudah menguasai kemampuan bahasa yang lain. Seperti yang diungkapkan oleh Ashari \& Shalehoddin (2018) bahwa minat belajar anak usia dini dapat meningkat dengan signifikan apabila metode dan pendekatannya sesuai, salah satunya yaitu dengan metode bermain sehingga dalam propses belajar anak tetap bersemangat dan tidak merasa terbebani dalam belajar Bahasa Inggris.

Pembelajaran interaktif yang dilakukan pada kegiatan ini bertujuan untuk dapat meningkatkan kosa kata Bahasa Inggris dengan cara bernyanyi, sehingga diharapkan anak lebih mampu dan mudah, serta lebih cepat mengenal Bahasa Inggris. Permasalahan yang timbul umumnya yaitu pada pelafalan Bahasa Inggris yang masih sulit diucapkan dengan benar dan masih bersifat seadanya. Berdasarkan dari hal ini, maka untuk memahami Bahasa Inggris dengan metode bernyanyi dirasakan sangatlah tepat untuk anak usia dini, karena bernyanyi diharapkan dapat menjadi salah satu jembatan pembelajaran interaktif untuk lebih memudahkan dalam pembelajaran dan hal ini juga selaras dengan Direktorat PADU (2010). Pembelajaran interaktif dengan menggunakan teknik bernyanyi merupakan salah satu pembelajaran yang sangat berperan dan hasilnya signifikan untuk anak usia dini, selain itu system pembelajaran interaktif ini juga sangat tepat karena akan selalu diingat dalam memori anak usia dini.

Seperti yang kita ketahui bahwa anak usia dini pemahamannya belum mencapai seperti layaknya orang dewasa sehingga perlu teknik khusus ataupun metode yang tepat agar dapat dipahami dengan mudah dan membuat anak nyaman dan tidak terbebani pada saat mengingat kosa kata dalam Bahasa Inggris. Seperti yang diungkapkan oleh Keraf (2009) kosa kata adalah unsur bahasa yang memiliki peran penting dalam pengembangan keterampilan bahasa yang meliputi berbicara, mendengar, membaca dan menulis yang merupakan perwujudan kesatuan perasaan dan fikiran yang dapat digunakan dalam penggunaanya. Sedangkan menurut Martinus (2011) kosakata merupakan salah satu aspek bahasa yang sangat penting keberadaannya. Kosakata diartikan sebagai perbendaharaan kata. Adapun jalan yang ditempuh untuk menguasai kosa kata adalah dengan metode menghafal. Namun 
tanpa strategi yang tepat, kegiatan menghafal membuat anak-anak frustasi dan menyerah di langkah awal sebelum mereka menguasai beberapa puluhan kata. Mempelajari kosa kata adalah aspek penting dari perkembangan bahasa. Dapat disimpulkan bahwa kosa kata adalah keseluruhan kata atau perbendaharaan kata atau istilah yang mengacu pada konsep-konsep tertentu yang berhubungan dengan bahasa yang harus dimiliki oleh seorang anak sehingga bisa berkomunikasi dalam suatu lingkungan.

Pembelajaran untuk anak-anak usia dini juga memiliki karakteristik yang berbeda dengan pembelajar dewasa. Menurut Harmer (2001) setidaknya ada tujuh sifat belajar anakanak yang berbeda dengan orang dewasa. Di antara sifat itu adalah anak akan merespon terhadap makna walaupun mereka tidak mengerti semua kata-kata secara keseluruhan. Anakanak juga cenderung belajar dari lingkungan sekitar. Mereka belajar tidak hanya dari apa yang di dengar dan dilihat tetapi juga dari apa yang mereka lakukan. Selaian itu anak-anak juga memiliki waktu untuk konsentrasi yang terbatas. Dengan adanya perbedaan sifat tersebut, perlakuan terhadap anak-anak juga harus berbeda dengan perlakuan terhadap pembelajar dewasa. Lebih jauh, menurut Claire (1988), anak-anak belajar dengan menggunakan seluruh panca indra mereka. Total physical response adalah cara yang pada beberapa hal baik untuk memfasilitasi anak-anak belajar. Agar tujuan pembelajaran bahasa Inggris bisa tercapai secara baik, salah satu caranya yaitu menciptakan suasana dan kondisi belajar menyenagkan. Ada beberapa sumber belajar yang menguntungkan bagi anak anak yaitu seperti lagu, cerita, permainan, dan juga crafting (keterampilan).

Aktivitas mendengarkan lagu umumnya memberikan kesempatan lebih banyak bagi anak untuk berkomunikasi setelah mereka mendengarkan lagu. Selain lagu sumber belajar yang dapat digunakan yaitu bercerita. Menurut Wright (1995), cerita memuat sejumlah banyak kata, menyajikan pengalaman bahasa yang kaya. Selain itu cerita juga mampu memotivasi dan tidak mahal. Sumber belajar lainnya yang bisa dipakai yaitu dengan permainan. Menurut Toth (1995) dalam Mei and Yu-Jung( 2000) mendefinisikan permainan sebagai aktivitas yang memiliki aturan, tujuan dan di dalamnya terkandung unsur rasa senang. Fokus dari permainan bukan pada ketepatan bahasa tapi pada komunikasi. Sedangkan menurut Richard dkk (2002) permainan adalah: “a) particular task or objective; b) a set of rules; c) competition between players; d) communication between players by spoken or 
written language." Brewster dkk (2002) juga menuliskan bahwa dengan permainan siswa bisa belajar bahasa dalam suasana yang rileks dan menyenangkan. Selain lagu, bercerita, dan permainan, sumber belajar yang dapat digunakan untuk anak yaitu crafting. Crafting melatih anak mengembangkan otak juga otot motoriknya. Namun pada kegiatan ini, tim pengabdian kepada masyarakat hanya berfokus pada aktifitas mendengarkan lagu untuk menambah kosa kata Bahasa Inggris untuk anak-anak.

\section{METODOLOGI}

Dalam kegiatan Pendampingan Metode Belajar Menyenangkan (Fun Learning) Untuk Meningkatkan Pemahaman Kosa Kata Bahasa Inggris Pada Anak Usia Dini di kavling Saguba RW 03 Kelurahan Sungai Binti ini menggunakan metode Teaching English by using song. Metode ini adalah salah satu metode / cara mengajarkan Bahasa Inggris dengan menggunakan nyanyian / lagu sebagai medianya. Mengingat Bahasa Inggris merupakan bahasa asing di Indonesia, tentunya proses pembelajarannya memerlukan pendekatan yang tepat dan efektif. Nyanyian berfungsi sebagai alat untuk mencurahkan pikiran dan perasaan untuk berkomunikasi. Pada hakikatnya nyanyian bagi anak-anak adalah sebagai :

1. Bahasa Emosi, dimana dengan nyanyian anak dapat mengungkapkan perasaannya, rasa senang, lucu, kagum, haru.

2. Bahasa Nada, karena nyanyian dapat didengar, dapat dinyanyikan, dan dikomunikasikan.

3. Bahasa Gerak, gerak pada nyanyian tergambar pada birama (gerak/ ketukan yang teratur), pada irama (gerak/ketukan panjang pendek, tidak teratur), dan pada melodi (gerakan tinggi rendah).

Beberapa keuntungan mengajarkan Bahasa Inggris dengan menggunakan nyanyian juga akan memotivasi anak untuk lebih senang mempelajari Bahasa Inggris. Secara umum menyanyi bagi anak lebih berfungsi sebagai aktivitas bermain dari pada aktivitas pembelajaran atau penyampaian pesan. Menyanyi dapat memberikan kepuasan, kegembiraan, dan kebahagiaan bagi anak sehingga dapat mendorong anak untuk belajar lebih giat (Joyful Learning). Dengan nyanyian seorang anak akan lebih cepat mempelajari, menguasai, dan mempraktikkan suatu materi ajar yang disampaikan. Selain itu kemampuan anak dalam 
mendengar (listening), bernyanyi (singing), berkreativitas (creative) dapat dilatih melalui kegiatan ini. Seperti yang diunggkapkan oleh Sudjana (2004) bahwa sebuah metode berisikan cara belajar mengajar yang melibatkan siswa dengan mengalami dan membuktikan sendiri proses dan hasil percobaan. Penerapan dalam metode ini menggunakan penerapan EYL (English for Young Learner) pada anak-anak usia dini dengan tujuan meningkatkan pemahaman terhadap bahasa asing khususnya Bahasa Inggris. Adapun teknik dari metode ini adalah:

1. Melakukan survey untuk mengetahui sejauh mana anak-anak mengenal bahasa Inggris

2. Memberikan pengenalan langsung terhadap bahasa asing secara langsung pada sasaran didik.

3. Memberikan praktek kepada sasaran didik berupa pembelajaran bahasa inggris mendasar dengan nuansa Fun English secara berangsur

4. Mengevaluasi hasil dari pembelajaran.

Tujuan dari adanya tahapan-tahapan diatas adalah untuk meningkatkan minat anakanak terhadap bahasa asing sebagai sarana mengembangkan diri mereka. Semua tahapan dari metode ini harus dijalankan secara bertahap dan diperhatikan dengan baik agar hasil yang diharapkan dapat diperoleh. Untuk kegiatan Pendampingan Metode Belajar Menyenangkan (Fun Learning) dalam meningkatkan pemahaman kosa kata Bahasa Inggris pada anak usia dini ini dilaksanakan mulai tanggal 30 Agustus s/d 01 September 2019 yang berlokasi di kavling Saguba RW 03 Kelurahan Sungai Binti Kecamatan Sagulung Batam 


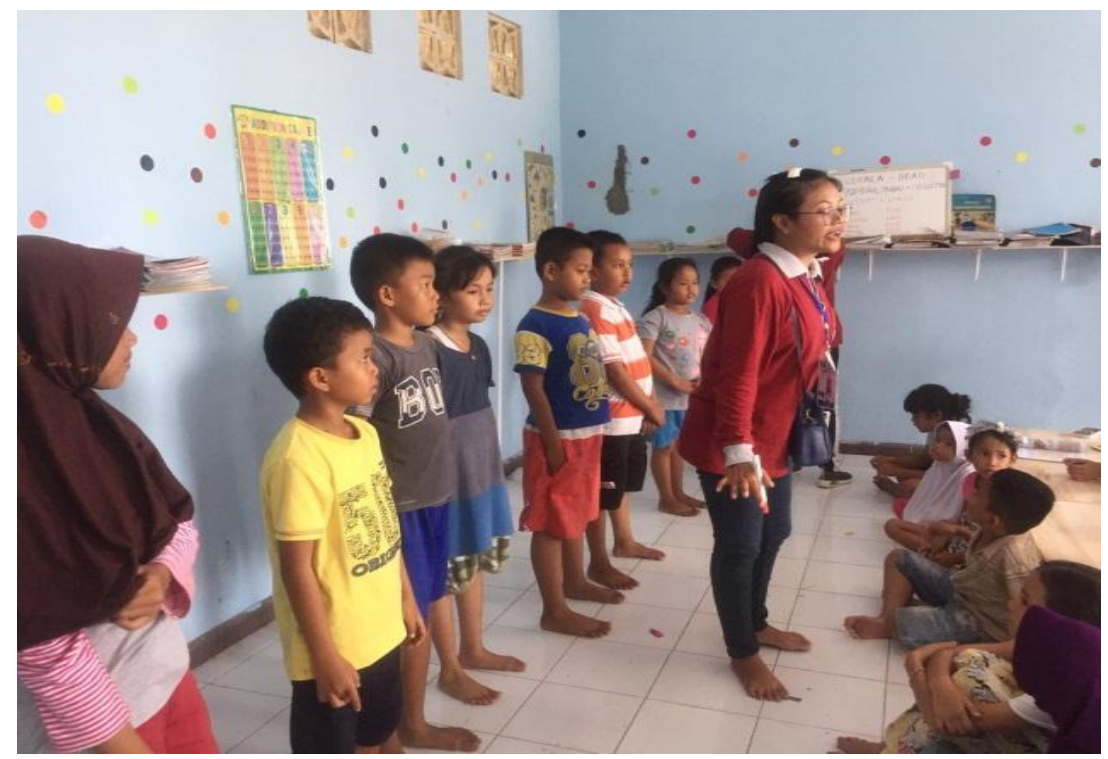

Figur 1. Foto Kegiatan di RW 03 Kelurahan Sungai Binti Batam

\section{HASIL DAN PEMBAHASAN}

Dalam kegiatan pengabdian kepada masyarakat khususnya program Pendampingan Metode Belajar Menyenangkan (Fun Learning) Untuk Meningkatkan Pemahaman Kosa Kata Bahasa Inggris Pada Anak Usia Dini di kavling Saguba RW 03 Kelurahan Sungai Binti yaitu merupakan kegiatan memberikan pengajaran. Pengajaran ini di dilakukan dengan melibatkan mahasiswa/i UNRIKA (Universitas Riau Kepulauan) dalam mentransformasikan ilmu yang didapat kepada anak-anak di wilayah RW 03 Kelurahan Sungai Binti Kecamatan Sagulung Batam dengan memberikan pelajaran dalam bahasa Inggris.

Dalam pelaksanaan kegiatan ini, patisipasi masyarakat cukup membantu dan mendorong kelancaran kegiatan program bimbingan belajar Bahasa Inggris. Bentuk partisipasi yang terjadi dalam masyarakat, antara lain;

1. Anak-anak di Wilayah RW 03 Kelurahan Sungai Binti Kecamatan Sagulung Batam semangat mengajak teman-teman dekatnya untuk datang dan ikut berlajar Bahasa Inggris

2. Beberapa orang tua juga antusias mengantar anak-anaknya untuk mengikuti bimbingan belajar yang diselenggarakan di Wilayah RW 03 Kelurahan Sungai Binti Kecamatan Sagulung Batam tepatnya di gedung manca (taman baca) . 
Doi. 10.33373/jmb.v4vi1.2056

Hal. 11-19

Hasil dari program dalam bidang pendidikan anak-anak di wilayah RW 03 Kelurahan Sei Binti Kecamatan Sagulung Batam, dapat disimpulkan:

1. Anak-anak di wilayah RW 03 Kelurahan Sei Binti Kecamatan Sagulung Batam mengenal Bahasa inggris sebagai Bahasa yang dapat di pakai di berbagai belahan dunia.

2. Anak-anak di wilayah RW 03 Kelurahan Sei Binti Kecamatan Sagulung Batam mulai mengetahui cara belajar memorizing 10 words a day yang memudahkan belajar bahasa inggris. Contohnya menghapal kosa kata yang berkaitan dengan anggota tubuh dalam bahasa inggris melalui lagu.

\section{KESIMPULAN DAN SARAN}

Kegiatan pengabdian kepada masyarakat ini memberikan pemahaman dan solusi terhadap apa yang terjadi didalam masyarakat. Adapun pemberdayaan dan pengabdian pada masyarakat yang dilakukan di wilayah RW 03 Kelurahan Sei Binti Kecamatan Sagulung Batam ini melibatkan sekelompok mahasiswa/I UNRIKA. Dan hasil dari pengajaran bahasa inggris yang dilakukan memberikan beberapa kemajuan yaitu;

1. Anak-anak di wilayah RW 03 Kelurahan Sei Binti Kecamatan Sagulung Batam mulai mengenal metode memorizing 10 words a day dalam belajar Bahasa inggris sebagai pembangun kemampuan utama dalam Bahasa Inggris yang berpangku pada vocabulary atau kosa kata.

2. Anak-anak di wilayah RW 03 Kelurahan Sei Binti Kecamatan Sagulung Batam mulai menyukai Bahasa Inggris dan berlomba menghafal vocabulary yang diujikan.

3. Anak-anak di wilayah RW 03 Kelurahan Sei Binti Kecamatan Sagulung Batam dapat mengucapkan dengan jelas kata-kata sederhana dalam Bahasa inggris.

\section{REFERENSI}

Ashari, E., \& Shalehoddin. 2018. Pengenalan Materi Dasar Bahasa Inggris Bagi Anak-Anak Usia Dini Di Pulau Mecan, Sekanak Raya, Belakang Padang, Batam. Minda Baharu, 2(1), 1-9. 
Brewster, J., Ellis, G., \& Girard, D. 2002. The primary English teacher's guide. London: Pearson plc.

Direktorat PADU. (2010) Informasi tentang Pendidikan Anak Usia Dini Pendidikan Pra Sekolah Pada Jalur Pendidikan Luar Sekolah, Jakarta: Direktorat PADU dirjen PLS Depdiknas.

Fauziati, E. (2010). Teaching English as a Foreign Language. Surakarta: Era Pustaka Utama.

Harmer, J. (2001). The Practice of English Language Teaching with DVD (4th Edition) London: Longman Handbooks for Language Teachers.

Hewlett, C., Ward, H., Roden, J., \& Foreman, J. 1(988). Teaching Science in the Primary Classroom: A Practical Guide (Paperback). London. SAGE Publications.

Hoed, B. (2011). Semiotik dan Dinamika Sosial Budaya. Jakarta: Komunitas Bambu

Keraf, G. (2009). Diksi dan Gaya Bahasa. Jakarta: Gramedia Pustaka Utama.

Martinus, S. (2011). Kamus Kata Serapan. Jakarta: Rineka Cipta.

Megah, S. I. (2019). Sosialisasi Dan Pembelajaran Kepada Anak Anak Tentang Pentingnya Penguasaan Bahasa Inggris. Minda Baharu, 3 (1), 16-25.

Mei, Yin Yong \& Yu-jing, J. (2000). From using games in an EFL class for children. Daejin University ELT Research Paper. Fall, 2000. http://english.daejin.ac.kr/ rtyson/fall2000/elt/games.html

Richard, J.C., Schmidt, R., Kendricks, H., \& Kim, Y. (2002). Longman Dictionary of Language Teaching and Applied linguistics. London: Pearson Education.

Sudjana, A. (2004). Dasar-Dasar Proses Belajar Mengajar. Bandung: Sinar Baru Algensido Offset

Wright, A. (1995). Story Telling with Children. Oxford: OUP. 